\title{
Iklim sekolah sebagai determinan semangat kerja guru sekolah menengah kejuruan
}

(School climate as the determinant of vocational high school teachers' work enthusiasm)

\author{
Tia Triyanah', Edi Suryadi ${ }^{*}$ \\ 1,2Program Studi Pendidikan Manajemen Perkantoran, \\ Fakultas Pendidikan Ekonomi dan Bisnis, Universitas Pendidikan Indonesia \\ Jl. Dr. Setiabudhi, No. 229 Bandung, Jawa Barat Indonesia \\ Email: edi_suryadi@upi.edu
}

\begin{abstract}
ABSTRAK
Penelitian ini bertujuan untuk mengetahui pengaruh iklim sekolah terhadap semangat kerja guru sekolah menengah kejuruan. Metode penelitian menggunakan survei eksplanatory. Teknik pengumpulan data menggunakan angket dengan skala 1 sampai dengan 5 model skala likert. Responden sebanyak 32 guru sekolah menengah kejuruan. Teknik analisis menggunakan regresi. Hasil penelitian menunjukkan bahwa terdapat pengaruh yang positif antara iklim sekolah terhadap semangat kerja guru. Dengan demikian semakin kondusif iklim sekolah, maka semakin tinggi tingkat semangat kerja guru.
\end{abstract}

Kata Kunci: iklim sekolah, semangat kerja

\begin{abstract}
The research aims to find about the influence of school climate on vocational high school teachers' work enthusiasm. It adopted an explanatory survey method. Data were collected with a 1-5 Likert scale questionnaire. The respondents consisted of 32 vocational high school teachers. Data were analyzed with regression technique. The findings show that school climate had positive influence on teachers' work enthusiasm. Therefore, the more conducive the school climate is, the higher teachers' enthusiasm will be.
\end{abstract}

Keywords: school climate, work enthusiasm

\section{PENDAHULUAN}

Semangat kerja guru merupakan salah satu masalah dalam dunia pendidikan yang menarik untuk dikaji. Semangat kerja guru merupakan aspek yang sangat penting dalam pelaksanaan pembelajaran (Govindarajan D. K., 2012), (Smith K. R., 1966). Guru merupakan unsur pokok dalam menunjang keberhasilan sekolah (Sari, 2016) dan memiliki peran sentral dalam pengembangan profesional guru (Bordhan, 2015). Selain itu, guru juga berperan penting dalam proses pengambilan keputusan sekolah (Sarafidou \& Chatziioannidis, 2013). Guru dianggap sebagai agen perubahan sosial (Shukla, 2014) dan faktor perbaikan sistem pendidikan (Neelam, 2014). Oleh karena itu, guru memiliki peran penting dalam dunia pendidikan (Chughati \& Perveen, 2013) karena sebagai aset utama (Aslam, 2012) dalam mencapai efektivitas sekolah (Chamundeswari, 2013). Seperti halnya yang diungkapkan oleh Lester bahwa semangat kerja guru penting dalam menentukan 
keberhasilan proses belajar mengajar (Kingoina, Kadenyi, \& Ngaruiya, 2015), (Berkovich, 2011).

Fakta di salah satu Sekolah Menengah Kejuruan swasta di Kota Bandung menunjukkan tingkat semangat kerja guru belum optimal. Hal ini ditunjukkan dengan tingkat kehadiran guru yang fluktuatif selama lima tahun terakhir, guru yang masuk kelas terlambat, guru keluar dari kelas lebih cepat dari jadwal yang telah ditentukan, dan kegiatan belajar mengajar yang kurang menarik. Mengingat semangat kerja guru sangat penting, maka untuk menanggulangi semangat kerja guru yang belum optimal, penelitian ini merujuk pada teori perilaku menurut Luthans (Luthans, 2005). Berdasarkan teori perilaku tersebut terdapat banyak faktor yang mempengaruhi semangat kerja. Menurut Zainun salah satu faktor tersebut adalah iklim sekolah (Asnawi, 1999), sehingga dijadikan kajian dalam penelitian ini.

Berdasarkan hal tersebut, maka rumusan masalah dari penelitian ini adalah "adakah pengaruh iklim sekolah terhadap semangat kerja guru?". Dengan demikian tujuan dari penelitian ini adalah untuk menganalisis pengaruh iklim sekolah terhadap semangat kerja guru.

\section{TINJAUAN PUSTAKA \\ Semangat Kerja}

Semangat kerja adalah perilaku individu (Siswanto, 2002) dan kelompok (Tohardi, 2002) dalam melakukan pekerjaan secara lebih giat, lebih cepat, dan lebih baik (Nitisemito, 2002). Semangat kerja menunjukkan iklim dan suasana pekerja (Handoko, 2004). Menurut Moekijat semangat kerja akan berdampak pada keterlibatannya terhadap pekerjaan dan organisasinya (Majorsy, 2007) sehingga dapat mencapai tujuan yang telah ditetapkan (Smith K. R., 1966).

Menurut Ellanberg, semangat kerja guru yang tinggi akan meningkatkan produktivitas kerja guru dan prestasi akademik siswa (Kingoina J. O., 2015), (Smith K. R., 1976). Young menyatakan apabila semangat kerja guru tinggi, maka akan berdampak baik pada semangat belajar dan prestasi siswa (Mackenzie, 2007), (Smith K. R., 1966). Semangat kerja merupakan bagian dari organisasi sosial (Brady J. , 2007), dimana guru yang memiliki semangat kerja dapat menciptakan kreativitas, inovasi (Linz, Good, \& Huddleston, 2006), memiki kecerdasan (Mitroff \& Denton, 1999), dan dapat mencari peluang dalam berbagai aspek (Ashmos \& Duchon, 2000). Semangat kerja berarti memiliki gairah dan energi (Kinjerski \& Skrypnek, Defining Spirit at Work Finding Common Ground, 2004) yang ditunjukkan pada saat terlibat dalam pekerjaan (Taormina \& Gao, 2008).

Terdapat empat indikator yang dapat mengukur semangat kerja yaitu disiplin, tanggung jawab, antusiasme, dan loyalitas (Siswanto, 2002). Disiplin adalah suatu sikap menghormati, menghargai, patuh, dan taat terhadap peraturan-peraturan yang berlaku, baik yang tertulis maupun tidak tertulis serta sanggup menjalankannya dan tidak mengelak untuk menerima sanksi-sanksinya apabila ia melanggar tugas dan wewenang yang diberikan kepadanya. Tanggung jawab adalah kesadaran individu akan tingkah laku atau perbuatan yang disengaja maupun yang tidak di sengaja. Tanggung jawab juga berarti berbuat sebagai perwujudan kesadaran akan kewajibannya. Loyalitas adalah salah satu unsur yang digunakan dalam penilaian karyawan yang mencakup kesetiaan terhadap pekerjaannya, jabatannya dan organisasi. Kesetiaan ini dicerminkan oleh kesediaan karyawan menjaga dan membela organisasi di dalam maupun di luar pekerjaan.

Zainun menyatakan bahwa faktor-faktor yang mempengaruhi semangat kerja yaitu (1) hubungan yang harmonis antara pimpinan dan bawahan; (2) kepuasan para karyawan terhadap tugas dan pekerjaan karena memperoleh tugas yang disukai sepenuhnya; (3) 
terdapatnya suatu suasana dan iklim yang bersahabat sehingga mampu meningkatkan semangat kerja karyawan; (4) rasa kemanfaatan bagi tercapainya tujuan organisasi yang juga merupakan tujuan bersama-sama; (5) adanya tingkat kepuasan ekonomi sebagai imbalan yang dirasakan adil terhadap jeri payah yang telah diberikan oleh organisasi dan; (6) adanya ketenangan jiwa, jaminan kepastian serta perlindungan terhadap segala sesuatu yang dapat membahayakan diri pribadi dan karier dalam pekerjaan (Asnawi, 1999).

\section{Iklim Sekolah}

Iklim sekolah memainkan peran penting untuk mengembangkan sekolah yang sehat dan positif (Babatunde \& Olanrewaju, 2014). Menurut Cohen et al. iklim sekolah yang positif akan memajukan proses belajar mengajar (Barnes, Brynard, \& Wet, 2012) dan meningkatkan pengajaran yang efektif (Rapti, 2012). Hal ini sejalan dengan pendapat Benard, Resnick et al., dan Thapa \& Cohen mengatakan bahwa iklim sekolah yang positif dapat mengurangi hambatan siswa pada saat proses belajar mengajar (Jain, Cohen, Huang, Hanson, \& Austin, 2015) sehingga dapat meningkatkan prestasi siswa (Voight, Hanson, OMalley, \& Adekanye, 2015), kepuasan kerja guru (Galvez, Cruz, \& Diaz, 2016) dan efektivitas sekolah (Pashiardis, 2008). Brookover dan Lezzote mengatakan bahwa iklim sekolah penting dalam meningkatkan kesuksesan sekolah (Pashiardis, 2008).

Haynes, Emmons \& Comer menyatakan iklim sekolah sebagai kualitas interaksi antarpersonal (Hoffman, Hutchinson, \& Reiss, 2009), persepsi dari antarpersonal (Tajasom \& Ahmad, 2011) dan kualitas karakteristik kehidupan di lingkungan sekolah (Pourrajab, Roustaee, Talebloo, Kasmaienezhadfard, \& Ghani, 2015), (Voight, Hanson, OMalley, \& Adekanye, 2015) yang bergantung pada kepemimpinan kepala sekolahnya (Brady L. , 1988). Brookover et al. menyatakan bahwa iklim sekolah merupakan sistem sosial di lingkungan sekolah (Tajasom \& Ahmad, 2011) yang dapat mempengaruhi perilaku guru (Hoy, Hoffman, Sabo, \& Bliss, 1996), kepuasan kerja guru (Jain, Cohen, Huang, Hanson, \& Austin, 2015), (Sahney, 2016) dan tingkat ketidakhadiran guru di sekolah (Lishchinsky \& Rosenblatt, 2010).

Moos dan Arter mengemukakan bahwa iklim sekolah dapat diukur dengan empat indikator yaitu indikator hubungan antar personal, indikator pertumbuhan atau perkembangan pribadi, indikator perubahan dan perbaikan sistem, dan indikator lingkungan fisik (Hadiyanto, 2004). Hubungan antar personal mengukur sejauh mana keterlibatan personalia yang ada di sekolah seperti kepala sekolah, guru, dan peserta didik saling mendukung dan membantu sejauh mana mereka dapat mengekspresikan kemampuan mereka secara bebas dan terbuka. Pertumbuhan dan perkembangan pribadi atau disebut juga dimensi berorientasi pada tujuan utama sekolah dalam mendukung pertumbuhan atau perkembangan pribadi dan motivasi diri guru untuk tumbuh dan berkembang. Perubahan dan perbaikan ini membicarakan sejauh mana iklim sekolah mendukung harapan, memperbaiki kontrol, dan merespon perubahan. Lingkungan fisik. membicarakan sejauh mana lingkungan fisik dapat mendukung harapan pelaksanaan tugas.

\section{METODOLOGI}

Metode yang digunakan dalam penelitian ini adalah metode penelitian survey explanatory. Metode ini dianggap tepat karena penelitian ini dilakukan untuk mengumpulkan informasi faktual melalui penggunaan kuesioner. Jumlah responden dalam penelitian ini sebanyak 32 orang guru salah satu Sekolah Menengah Kejuruan swasta di Kota Bandung.

Instrumen pengumpulan data berupa angket skala 1 sampai dengan 5 model skala likert yang terdiri atas 2 bagian. Bagian pertama adalah kuesioner untuk mengukur persepsi responden mengenai iklim sekolah yang dijabarkan dari empat indikator yaitu 
hubungan antar personil, petumbuhan dan perkembangan pribadi guru, perubahan dan perbaikan sistem, dan lingkungan fisik. Bagian ini terdiri atas 13 item. Bagian kedua adalah kuesioner untuk mengukur persepsi responden mengenai semangat kerja yang dijabarkan atas empat indikator yaitu disiplin, tanggung jawab, antusiasme, dan loyalitas. Bagian ini terdiri atas 17 item.

Statistik deskriptif menggunakan persentase yang digunakan untuk memperoleh gambaran tingkat persepsi responden mengenai kondusivitas iklim sekolah, dan tingkat semangat kerja guru. Statistik inferensial menggunakan analisis regresi yang digunakan untuk menguji hipotesis.

\section{HASIL PENELITIAN DAN PEMBAHASAN Iklim Sekolah}

Berdasarkan jawaban responden terhadap angket yang disebarkan, diperoleh hasil sebesar 49,5\% responden menyatakan iklim sekolah berada pada kategori kondusif. Hal ini menunjukkan bahwa iklim sekolah dapat menunjang kegiatan yang dilakukan di lingkungan sekolah. Berdasarkan indikator yang dijadikan kajian, jawaban responden terhadap angket yang disebarkan tampak pada Tabel 1 .

\section{Tabel 1 Iklim Sekolah}

\begin{tabular}{|l|c|c|}
\hline \multicolumn{1}{|c|}{ Indikator } & Persentase (\%) & Keterangan \\
\hline Hubungan antar Personil & 53,1 & Kondusif \\
\hline Pertumbuhan dan Perkembangan & 52,1 & Kondusif \\
\hline Pribadi Guru & & Kondusif \\
\hline Perubahan dan Perbaikan Sistem & 54,2 & Sangat Kondusif \\
\hline Lingkungan Fisik & 53,9 & \\
\hline
\end{tabular}

Tabel 1 menunjukkan sebesar 54,2\% responden menyatakan perubahan dan perbaikan sistem berada pada kategori kondusif, sebesar 53,9\% responden menyatakan lingkungan fisik berada pada kategori sangat kondusif, kemudian sebesar 53,1\% responden menyatakan hubungan antar personil berada pada kategori kondusif, dan sebesar 52,1\% responden menyatakan pertumbuhan dan perkembangan pribadi guru berada pada kategori kondusif. Data tersebut memberikan gambaran bahwa perubahan dan perbaikan sistem memberikan kontribusi terbesar terhadap iklim sekolah.

\section{Semangat Kerja}

Berdasarkan jawaban responden terhadap angket yang disebarkan, diperoleh hasil sebesar $57,7 \%$ responden menyatakan semangat kerja berada pada kategori tinggi. Hal ini menunjukkan bahwa semangat kerja guru tinggi sehingga guru dapat melaksanakan pekerjaan di lingkungan sekolah secara maksmimal. Berdasarkan indikator yang dijadikan kajian, jawaban responden terhadap angket yang disebarkan tampak pada Tabel 2.

Tabel 2 Semangat Kerja

\begin{tabular}{|l|c|c|}
\hline \multicolumn{1}{|c|}{ Indikator } & Persentase $\mathbf{( \% )}$ & Keterangan \\
\hline Disiplin & 65,6 & Tinggi \\
\hline Tanggung Jawab & 60,2 & Tinggi \\
\hline Antusiasme & 62,5 & Tinggi \\
\hline Loyalitas & 48,4 & Tinggi \\
\hline
\end{tabular}


Tabel 2 menunjukkan sebesar 65,6\% responden menyatakan disiplin berada pada kategori tinggi, sebesar $62,5 \%$ responden menyatakan tanggung jawab berada pada kategori tinggi, kemudian sebesar $60,2 \%$ responden menyatakan tangung jawab berada pada kategori tinggi, dan sebesar $48,4 \%$ responden menyatakan loyalitas berada pada kategori tinggi. Data tersebut memberikan gambaran bahwa disiplin merupakan cerminan dari semangat kerja yang paling dominan dibandingkan dengan indikator lainnya.

\section{Iklim Sekolah sebagai Determinan Semangat Kerja Guru Sekolah Menengah Kejuruan}

Persamaan regresi linier sederhana untuk hipotesis variabel iklim sekolah terhadap semangat kerja guru adalah: $\hat{Y}=9,532+1,002(X)$. Tanda positif $(+)$ menunjukkan hubungan antara variabel bebas dengan variabel terikat berjalan satu arah, sehingga apabila semakin kondusif iklim sekolah, maka semakin tinggi semangat kerja guru begitupun sebaliknya. Uji hipotesis, diperoleh nilai $F_{\text {hitung }}$ lebih besar dari nilai $F_{\text {tabel }}(30,38798>$ $4,17088)$ dengan $\mathrm{db} 1=1, \mathrm{db} 2=2=\mathrm{n}-2$ dan $\alpha=0,05$, yaitu $\mathrm{F}_{(0,05 ; 1 ; 30)}=4,17088$. Dengan demikian nilai koefisien determinasi, dapat diketahui bahwa besarnya pengaruh iklim sekolah terhadap semangat kerja guru sebesar 23,45\% sedangkan 76,55\% dipengaruhi oleh faktor-faktor lain yang tidak diteliti dalam penelitian ini.

Hasil ini sejalan dengan pendapat Hoy dan Miskel bahwa ketika lingkungan sekolah kondusif maka semangat kerja guru tinggi (Kingoina, Kadenyi, \& Ngaruiya, 2015). Semangat kerja yang positif dapat mempengaruhi tingkat efektivitas sekolah (Earthman \& Lemasters, 2009). Hasil ini juga sejalan dengan beberapa pendapat para ahli mengenai keterkaitan iklim dengan semangat kerja guru. Hasil menyimpulkan bahwa terdapat hubungan antara iklim organisasi dengan semangat kerja guru (Thaninayagam , 2014). Selain itu, iklim sekolah juga menciptakan hubungan antara kepala sekolah, guru , siswa, orang tua dan masyarakat (Pourrajab, Roustaee, Talebloo, Kasmaienezhadfard, \& Ghani, 2015). Semangat kerja guru yang tinggi akan meningkatkan prestasi belajar siswa (Govindarajan D. K., 2012). Menurut Freiberg et al. menyatakan bahwa iklim sekolah yang positif dapat menghasilkan hasil pendidikan dan psikologis yang positif terhadap siswa dan personil sekolah lainnya (Babatunde \& Olanrewaju, 2014) diantaranya meningkatkan semangat kerja guru (Wong, 1991) dan prestasi belajar siswa (Uline \& Moran, 2008) (Sahney, 2016).

\section{KESIMPULAN}

Iklim sekolah salah satu Sekolah Menengah Kejuruan swasta di Kota Bandung berada pada kategori kondusif, yang diukur melalui empat indikator yaitu hubungan antar personil, pertumbuhan atau perkembangan pribadi guru, perubahan dan perbaikan sistem, dan lingkungan fisik. Semangat kerja guru salah satu Sekolah Menengah Kejuruan swasta di Kota Bandung berada pada kategori tinggi, yang diukur melalui empat indikator yaitu disiplin, tanggung jawab, antusiasme, dan loyalitas.

Kondusif tidaknya iklim sekolah berpengaruh positif terhadap semangat kerja guru. Yang artinya bahwa semakin kondusif iklim sekolah maka semakin tinggi tingkat semangat kerja guru.

\section{DAFTAR PUSTAKA}

Ashmos, D., \& Duchon, D. (2000). Spirituality at Work. Journal of Management Inquiry, 9, 134-45. 
Aslam, R. (2012). Investigating the Relationship of OCB with Job Satisfaction, Organizational Commitment and Turnover Intensions (A case study on teaching staff of University of the Punjab). International Journal of Economics and Management Sciences, 1(9), 90-100.

Asnawi, S. (1999). Aplikasi Psikolgi dalam Manajemen Sumber Daya Manusia Perusahaan. Jakarta: Pusgrafin.

Babatunde, M. M., \& Olanrewaju, M. K. (2014). Class Size and School Climate as Correlates of Secondary School Students' Scholastic Achievement in Itesiwaju Local Government Area of Oyo State, Nigeria. Global Journal of Human-Social Science: G Linguistics \& Education, 14(3), 14-21.

Barnes, K., Brynard, S., \& Wet, C. d. (2012). The influence of school culture and school climate on violence in schools of the Eastern Cape Province. South African Journal of Education, 32(1), 69-82.

Berkovich, I. (2011). No We Wont Teachers Resistance to Educational Reform. Journal of Educational Administration, 49(5), 563 - 578.

Bordhan, S. (2015). Job satisfaction of teacher educators in relation to sex, qualification, experience and age at secondary level in Kamrup and Nagaon districts of Assam. International Journal of Multidisciplinary Research and Development, II(3), 703706.

Brady, J. (2007). A Pilot Study of Teacher Morale in Three Secondary Schools in The North of England. Journal of Educational Administration, 14(1), 94-106.

Brady, L. (1988). The Principal as A Climate Factor in Australian School: A Review of Studies. The Journal of Educational Administration, 26(1), 74-82.

Chamundeswari, S. (2013). Job Satisfaction and Performance of School Teacher. International Journal of Academic Research in Business and Social Sciences, 3(5), 420-428.

Chughati, F. D., \& Perveen, U. (2013). A Study of Teachers Workload and Job Satisfaction in Public and Private Schools at Secondary Level in Lahore City Pakistan. Asian Journal of Social Sciences \& Humanities, 2(1), 202-214.

Earthman, G. I., \& Lemasters, L. K. (2009). Teacher Attitudes About Classroom Conditions. Journal of Educational Administration, 47(3), 323 - 335.

Galvez, I. E., Cruz, F. J., \& Diaz, J. F. (2016). Evaluation of The Impact of Quality Management Systems on School Climate. International Journal of Educational Management, 30(4), 474 - 492.

Govindarajan, D. K. (2012). Teachers Morale. International Journal of Behavioral SocialL and Movement Sciences, I(2), 57-61.

Hadiyanto. (2004). Mencari Sosok Desentralisasi Manajemen Pendidikan di Indonesia. Bandung: PT Rineka Cipta.

Handoko, H. (2004). Manajemen Personalia dan Sumber Daya Manusia. Yogyakarta: BPFE-UGM.

Hoffman, L. L., Hutchinson, C. J., \& Reiss, E. (2009). On Improving School Climate: Reducing Reliance On Rewards And Punishment. International Journal of Whole Schooling, V(1), 13-24. 
Hoy, W. K., Hoffman, J., Sabo, D., \& Bliss, J. (1996). The Organizational Climate of Middle Schools: The Development and Test of The OCDQ-RM. Journal of Educational Administration, 34(1), 41-59.

Jain, S., Cohen, A. K., Huang, K., Hanson, T. L., \& Austin, G. (2015). Inequalities in School Climate in California. Journal of Educational Administration, 53(2), 237 261.

Kingoina, J. O. (2015). Head Teachers Perception on Teachers Morale toward Instructional Work in Public Primary School in Kegogi Division Marani Kenya. International Journal of Social Science and Humanities Research, III(4), 167-174.

Kingoina, O. J., Kadenyi, M. M., \& Ngaruiya, N. B. (2015). Effect of Teachers' Morale on Standard Eight Pupils' Academic Achievement in Public Primary Schools in Marani Sub-County, Kenya. International Journal of Scientific and Research Publications, V(10), 1-9.

Kinjerski, V., \& Skrypnek, B. J. (2004). Defining Spirit at Work Finding Common Ground. Journal of Organizational Change Management, 17(1), 26-42.

Linz, S. J., Good, L. K., \& Huddleston, P. (2006). Worker Morale in Russia: an Exploratory Study. Journal of Managerial Psychology, 21(5), 415 - 437.

Lishchinsky, O. S., \& Rosenblatt, Z. (2010). School Ethical Climate and Teachers Voluntary Absence. Journal of Educational Administration, 48(2), 164 - 181.

Luthans, F. (2005). Organizational Behavior. New York: McGraw-Hill.

Mackenzie, N. (2007). Teacher morale: More complex than we think? The Australian Educational Researche, 34(1), 89-104.

Majorsy, U. (2007). Kepuasan Kerja, Semangat Kerja, dan Komitmen Organisasional pada Staf Pengajar Universitas Gunadarma. Jurnal Psikologi, I(1), 63-74.

Mitroff, I., \& Denton, E. (1999). A Study of Spirituality in The Workplace. Sloan Management Review, 40(4), 83-92.

Neelam. (2014). A Study of Job Satisfaction Among Primary School Teachers in Relation to Their Demographic Variables. Teachers in Relation to Their Demographic Variables, $I V(2), 46-57$.

Nitisemito, A. S. (2002). Manajemen Personalia: Manajemen Sumber Daya Manusia. Jakarta: Ghalia Indonesia.

Pashiardis, G. (2008). Toward a Knowledge Base for School Climate in Cyprus Schools. International Journal of Educational Management, 22(5), 399 - 416.

Pourrajab, D. M., Roustaee, R., Talebloo, B., Kasmaienezhadfard, S., \& Ghani, A. M. (2015). School Climate and Parental Involvement: The Perception of Iranian Teachers. Global Journal of Commerce \& Management Perspective, IV(1), 24-33.

Rapti, D. (2012). School Climate as an Important Component in School Effectiveness. International Scientific Journal, 111-125.

Sahney, V. D. (2016). School Leadership and Its Impact on Student Achievement: The Mediating Role of School Climate and Teacher Job Satisfaction. International Journal of Educational Management, 30(6), 1-30. 
Sarafidou, J. O., \& Chatziioannidis, G. (2013). Teacher Participation in Decision Making and Its Impact on School and Teachers. International Journal of Educational Management, 27(2), 170-183.

Sari, D. P. (2016). Hubungan Iklim Sekolah dengan Semangat Kerja Guru SMK Swasta se-Kota Padang Panjang. Jurnal Administrasi Pendidikan, 1.

Shukla, S. (2014). Teaching Competency, Professional Commitment and Job SatisfactionA Study of Primary School Teachers. Journal of Research \& Method in Education, IV (3), 44-64.

Siswanto, B. (2002). Manajemen Tenaga Kerja Indonesia. Jakarta: PT Bumi Aksara.

Smith, K. R. (1966). A Proposed Model for the Investigation of Teacher Morale. Journal of Educational Administration, 4(2), 143-148.

Smith, K. R. (1976). Morale A Refinement of Stogdills Model. Journal of Educational Administration, 14(1), 87-93.

Tajasom, A., \& Ahmad, Z. A. (2011). Principals Leadership Style and School Climate: Teachers Perspectives From Malaysia. International Journal of Leadership in Public Services, 7(4), 314 -333.

Taormina, R. J., \& Gao, J. H. (2008). A Comparison of Work Enthusiasm and Its Antecedents Across Two Chinese Culture. Journal of Asia Business Studies, 2(2), 13-22.

Thaninayagam , D. V. (2014). Organizational Climate and Teachers Morale in the Higher Secondary Schools of. International Journal of Scientific Research, III(11), 132136.

Tohardi, A. (2002). Pemahaman Praktis Manajemen Sumber Daya Manusia. Jakarta: CV Mandar Maju.

Uline, C., \& Moran, M. T. (2008). The Walls Speak: The Interplay of Quality Facilities, School Climate, and Student Achievement. Journal of Educational Administration, 46(1), 55-73.

Voight, A., Hanson, T., OMalley, M., \& Adekanye, L. (2015). The Racial School Climate Gap: Within-School Disparities in Students' Experiences of Safety, Support, and Connectedness. American Journal of Community Psychologi, 56, 252-267.

Wong, R. Y. (1991). Construct Validation of the Staff Morale Questionnaire Staff Morale Questionnaire. Journal of Educational Administration, 29(1), 71-80. 